\title{
The Ontario New Universities Library Project-an Automated Bibliographic Data Control System
}

ONULP was established in 1963 to develop and maintain five 35,000volume academic libraries, and automated bibliographic control was planned from the beginning. Complete bibliographic information is keyed into a master record, which is then manipulated, selected, and reformatted for printout as shelf-list cards, author-title book catalogs, and subject book catalogs. Other bibliographic services can now be conducted as "by-products," including cooperative, analytical, control, and other activities.

The IMMEdiate OBJective of THE Ontario New Universities Libraky Project

I IN The LATE SUmmer of 1963 the University of Toronto library received from the government of the Province of Ontario a request to compile by 1967 five 35,000 -volume basic college library collections along with the necessary catalogs for five new Ontario universities and colleges, some of which had to enroll their first classes in September 1964. The task appeared to be a dual one. In the first place, it was necessary to select, acquire, and process approximately $\$ 35$,000 worth of books monthly; for this purpose a special project group had to be established. Second, it required a system of catalog production that could accommodate this acquisition rate as well as keep currently updated five sets of catalogs in five different institutions.

In October 1963 the Ontario New Universities Library Project (ONULP) was established with its own budget which included $\$ 1,300,000$ for the pur-

Mr. Bregzis is Assistant Librarian in the University of Toronto library. chase of books over a period of three and one-half years. The administrative organization of the project was set up in the form of the customary three basic operations: selection, acquisition, and cataloging. The selection of the materials was arranged to be done by the undergraduate book selection office of the University of Toronto library with added project staff. For the acquisition and processing of the selected materials two sections were established under the technical services of the University of Toronto library.

Since the processing of the ONULP materials was to be done as a separate project not integrated with the acquisition and cataloging of the materials of the University of Toronto library, an opportunity presented itself to choose the most suitable method for compiling the required catalogs.

The expert advice of the Institute of Computer Science of the University and the readiness of the IBM Toronto Data Centre to develop the machine system made it possible to proceed with work immediately.

The immediate problem for the 
ONULP participants was to have functional catalogs which could not only list the receipts from the project promptly and accurately but also integrate materials acquired by the participants themselves outside of the project. The experience of the University of Toronto library with multiple catalog maintenance indicated that these requirements could not be met economically by customary card catalogs. Since to meet this situation the need for book form catalogs was indicated, it became apparent that electronic data processing methods could be used advantageously for their compilation as well as for the bibliographic control of the library collections of the five new institutions.

The Long Term Objectives and the

Problem of Bibliographic Control

Bibliographic control of a library collection essentially is control of information macro-units and includes the whole range of organization of bibliographic data for various conceivable purposes. The bibliographic information customarily given on catalog cards constitutes only part of the information that a library requires for its services. The real long-term need therefore is for the library to develop a bibliographic control system which can supply not only the customary bibliographic tools, i.e., catalogs, but which can be used also to obtain quickly, reliably, and economically any type and selection of information pertaining to any part of the total collection of the library. Since electronic data processing methods permit such a total and flexible approach, and since such an approach appeared to be in the best long-term interests of the new institutions, the immediate task of solving the catalog compilation problem developed into a long-term objective of bibliographic control.

Bibliographic control sets a number of requirements which exceed those of customary library catalogs. First, a greater number of aspects of the biblio- graphic unit, i.e., the book, is incorporated in the master record, rather than a selection of such aspects. Second, all data have to be explicitly recorded and unmistakably identified rather than left to individual interpretation. Third, organization of data has to be rigidly systematic rather than aimed to serve immediate convenience. Moreover, the form of recording this information has to have flexibility and compatibility which can serve a variety of present and future uses, some of which will emerge as desirable only following further technological development in information processing.

The master record-a bibliographic information file in machine-readable form -therefore has to accommodate a number of services, some of which would be developed at a later date. A printout record of the collection, or shelf list, is the most essential of the required control records. Catalogs arranged by author, title, or subject and possibly classification are the most immediately required output forms to be generated from the machine-readable master record. Other services include specialized lists of books and reading lists by subject, language, etc.; periodic information to teaching staff regarding recent acquisitions in their respective fields of interest; records for automated circulation control; provision for tying in special subsystems, e.g., serials control; bibliographic data transmission to and from other institutions; financial and acquisition records; up-to-date working tools, e.g., subject lists; and statistical data regarding contents, patterns of use, and growth and size of the library collection.

\section{The Master Record-a Bibliographic InFormation FiLe in Machine- READABLE Form}

The format of the master bibliographic information file is designed to facilitate the developing of the services enumerated above. In addition, since the ONULP bibliographic control system 
Fig. 1-ONULP Data Sheet-
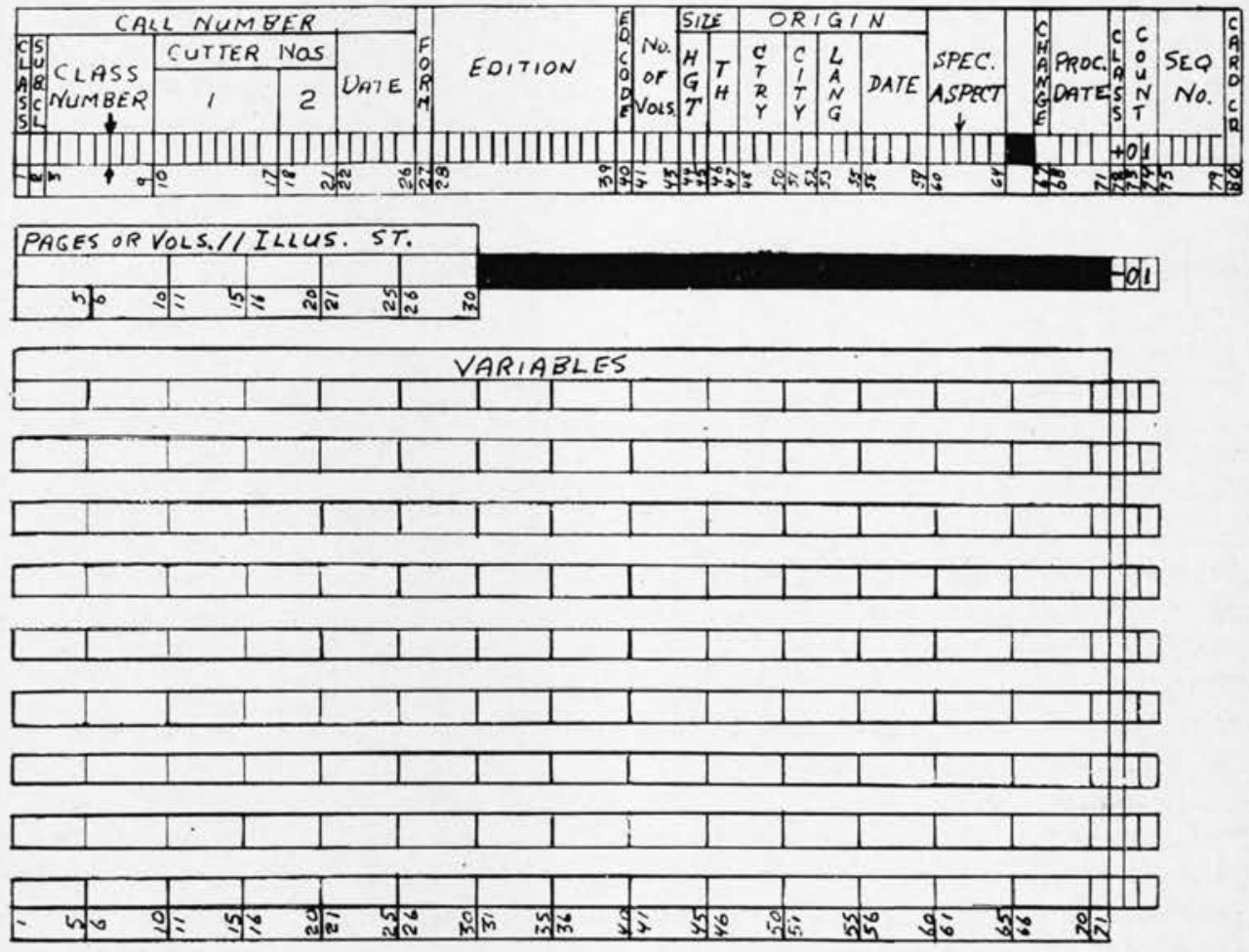

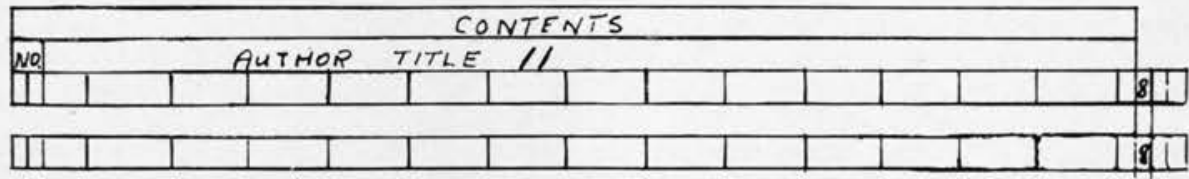

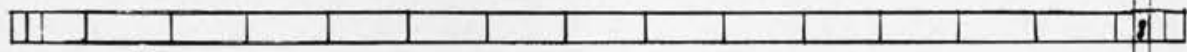

\begin{tabular}{|l|l|l|l|l|l|l|l|l|l|l|l|l|l|}
\hline 1 & & &
\end{tabular}

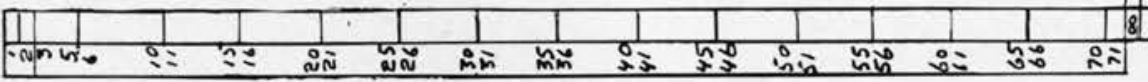

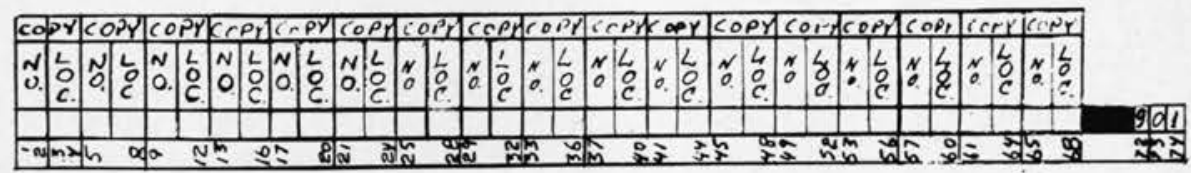


serves also as a pilot system for the study of the University of Toronto central library's automated bibliographic control requirements, extra features are incorporated which will permit testing of the present forms and methods of bibliographic expression, notably the system of catalog entry and that of subject terminology.

The master record is compiled by keypunching the bibliographic data into Hollerith cards and storing the information on magnetic tape. The data format of this master record, which is downward compatible with more general or less selective formats of properly identified bibliographic data, provides for a maximum length of fifteen hundred characters for each bibliographic unit (title) which is subdivided in variable length fields for the various categories of bibliographic information, which in turn subdivide into elements within a category. ${ }^{1}$ Each bibliographic unit, category of the unit, and element of the category is individually addressable. This arrangement allows for the various bibliographic data components to be processed and arranged in any desired combination.

The Master Record consists of a title record tape file which contains the complete information pertaining to the individual titles recorded, the name authority tape file, and the subject authority tape file. The authority files contain all names and subject terms that are necessary to cover the records for all titles as well as all references and history statements pertaining to the names in the name authority file and all references and scope notes pertaining to the subject terms in the subject authority file.

\footnotetext{
${ }^{1}$ This maximum was established as a multiple of the sum of the lengths of bibliographic data categories and elements as established in several surveys. The survey conducted by the University of Toronto library indicates somewhat higher character counts than the Columbia, Harvard, and Yale medical libraries' survey. Cf. Peter M. Sprenkle and Frederick G. Kilgour, "A Quantitative Study of Characters on Biomedical Catalogue Cards-a Preliminary Investigation," American Documentation, XIV (July 1963), 202-206. Fixed length fields are allotted for data categories and elements that by their nature are not likely to vary.
}

The data in the master record are identified by a system of codes which serve as addresses of the data units, categories, and elements, as well as provide the structural organization of these components. This structural code system permits addressing bibliographical data on any desired level of specificity.

For the compilation of the master record a specially designed data sheet is used which reflects the structure of the data format of this record (Fig. 1). The following categories of data constitute the record for each title:

1. Call number of the title. This category is further subdivided in the following elements:
a) main class.
b) subclass.
c) class number.
d) first Cutter number.
e) second Cutter number.
f) date.

2. Form of publication.

3. Brief edition statement.

4. Edition code.

5 . Number of volumes.

6. Size. This category consists of two elements:

a) height of the book.

b) thickness of the book.

7. Origin of the publication. This category is further subdivided in four elements:

a) country of origin.

b) city of origin.

c) language of the publication.

d) date of the publication.

8. Any special aspect other than those enumerated.

9. Paging and illustration statement. The two elements of this category can be separated if desired.

10. Principal author (main entry).

11. Conventional title.

12. Title.

13. Full length edition statement when different from 3 , above.

14. Imprint.

15. Series note.

16. Other notes (except Contents). 
17. Secondary bibliographic approaches (tracings). This category is subdivided in five elements as follows:

a) subject term. This element is further subdivided in the following forms:

i) name as subject term.

ii) topical subject term.

iii) descriptor term.

b) added entry (other than title and series ).

c) title added entry.

d) alternate title added entry.

e) series added entry.

Up to ten approaches of each group can be assigned to one title record.

18. Contents note. This category can be used in a systematic organization mode indicating the numbers or volumes of the contents. If so identified, the individual parts of the contents function as analytical approaches to the larger work.

19. Copy and location. This category consists of two elements:

a) copy number of the title.

b) location of the copy.

All data categories and elements, except for 1-9, are of variable length.

The data format of the name authority file and the subject authority file is comparably structured. During the required processing operations access to and utilization of the references, and history and scope notes recorded in these files, is performed automatically, based on a comparison between the names and subjects in the title record file and the authority files.

The information recorded on the data sheet is key punched using one Hollerith card for each line of data on the data sheet. All data are entered in the master record in the form of character codes designed to provide output in upper and lower case characters modified by diacritical marks where required. For this purpose an 026 keypunch with modified A-2 keyboard is used. The keypunched information is periodically converted to magnetic tape on a $8 \mathrm{~K}$ IBM
PN6080. K5 1958

card 1

King, William Francis Henry, 1843-1909, ed.

Classical and foreign quotations; a polyglot dictionary of historical and literary quotations, proverbs and popular sayings, compiled and edited, with translations and indexes. New York, F. Ungar [1958?] lxviii, $412 \mathrm{p}$.

\section{SEE NEXT CARD}

PN6080. K5 1958

card 2

1. Quotations I. Title

ERIN 1

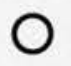

00404

Fig. 2-Shelf List Record Cards

JX1730. A4 E15

Eayrs, James Georges, 1926-

The art of the possible; government and foreign policy in Canada. [Toronto]

University of Toronto Press [1961] viii, $232 \mathrm{p}$.

Includes bibliography.

1. Canada-Foreign relations administration I. Title

BROC ERIN GLPH SCAR TREN

Fig. 3a-Author-Title Catalog Listing - MaIn Entry Record

1401 for processing on the IBM 7094 model II. The 7094 processing consists of extensive editing of the various codes, fields, and record lengths and of sorting the entire file in call number order. All required information in the desired output form is derived from this master record.

\section{The Catalog Compilation System}

At the present time the master record is used for the generation of shelflist cards and codex form catalogs of the project which were the immediately required tools for the ONULP bibliographic control system.

The automated catalog compilation 
The art of the possible

JX1730. A4 E15

Eayrs, James Georges, 1926-

The art of the possible 1961 viii, $232 \mathrm{p}$.

BROC ERIN GLPH SCAR TREN.

Fig. $3 b$-Author-Title Catalog Listing -Trtle Added ENTRy Record

Slonimsky, Nicolas, 1894-ed.

Baker, Theodore, 1851-1934

Biographical dictionary of musicians.

5th ed. $1958 \mathrm{xv}, 1855 \mathrm{p}$.

BROC ERIN GLPH SCAR TREN

Fig. 3c-Author-Title Catalog Listing -Name Added Entry Record

Bibliotheca biotheoretica, v. 9

QL799. R78

Russell, Edward Stuart, 1887-

$151 \mathrm{p}$.

BROC ERIN GLPH SCAR TREN

Fig. $3 d$-Author-Trteg Catalog Listing -Series Added EnTry Record

Austria-History-1867-1918

DB91. J3 1961

Jaszi, Oszkar, 1875-1957

The dissolution of the Habsburg Monarchy 1961 xiv, $482 \mathrm{p}$.

BROC ERIN GLPH SCAR TREN

May, Arthur James, 1899-

DB85. M35

The Hapsburg Monarchy, 1867-1914 $1960 \mathrm{x}, 532 \mathrm{p}$.

\section{BROC ERIN GLPH SCAR TREN}

Fig. 4-Subject Catalog Listing -Subject Entry Records system derives its effectiveness from the systematic structure of the data format of the master record, from which the required bibliographic information is selected and reformatted according to the formats of the shelflist cards (Fig. 2), the records in the author-title catalog (Fig. 3), and the subject catalog (Fig. 4). For the shelflist record "full catalog information" as defined by the ALA rules of entry and the Library of Congress rules for descriptive cataloging, is selected from the master record. Added to this information are also copy numbers and location designations. Similarly "full catalog information" is selected from the master record for the generation of the main entry record ${ }^{2}$ to be included in the author-title catalog.

Information used for all secondary entry records, however, is more selective, and certain categories of data are displayed in abbreviated form. The secondary entry records, both added entry records for the author-title catalog and subject entry records for the subject catalog contain only the call number, the secondary entry, the main entry, abbreviated title, brief edition statement, date of publication, and paging, as well as location information. The abbreviation of all secondary entry records is performed automatically by the computer. The only instances in this formatting where manual guidance is exercised are the insertion of a special character on the data sheet indicating the end of the brief title and the separation of paging from the illustration statement.

Since the master record tape file is in call number sequence, the shelflist records when produced are in proper filing sequence without any further rearrangement. Both the author-title and subject entry records, however, must be sorted in alphabetical sequence.

${ }^{2}$ In this paper a distinction between the terms "entry" and "entry record" is made. "Entry" refers only to the name (personal or corporate), title, or subject term under which a work is entered. "Entry record" refers to the whole record of a work displayed in a catalog; usually this term is qualified as main entry record, added entry record, or subject entry record. 
The filing arrangement of entry records in the catalog is designed to be performed automatically by the programed system without any attempt to regulate it at the time of preparing the bibliographic information input. It is assumed that the arrangement of entry records in the catalog depends more on the relative characteristics between these records than on the specific characteristics of the individual record.

Generally the filing order attempts to adhere to the customary sequencing of alphabetic information. The basic order of sequencing in this system is: blank, period, dash, comma, alphabetic characters $\mathrm{A}$ to $\mathrm{Z}$, and numeric characters 0 to 9 . This sequencing system is applied to filing of bibliographic units according to a computer-constructed filing field which consists of a specified number of characters from the key categories of the bibliographic unit. The selection of categories and number of characters in each category was based on sampling and analysis of appropriate sections of the University of Toronto library catalogs, and the selected lengths vary with the type of the entry record.

In applying this filing formula, the system disregards nine qualifying terms at the end of the entry. Another modification of principal importance is the disregarding of initial articles in all main and secondary title entries. A comprehensive list of articles in twenty-seven languages is used. Omission of an initial article found in this list is activated by the corresponding language code. Modest as these modifications of pure character-bycharacter filing are, they are impressively costly in terms of programing and operational factors.

The results of this filing arrangement are not expected to produce an arrangement identical to that specified by any of the customary filing rules. It is conceded that the customary semi-systematic filing arrangement cannot be justified by the complexity of the required programs and operational costs that would be involved in its attainment. Moreover, it is not certain that the public would find the customary filing sequences more convenient than considerably more standardized alphabetic arrangements. Further adjustments of the present filing formulas are expected to be necessary, and prolonged use of the ONULP catalogs should indicate the degree of validity of the basic sequencing system of the bibliographic information in the catalogs.

For the inclusion of references in the alphabetically-arranged title record tape file containing all main and secondary entry records, this file is matched with the name authority tape file. All references leading to names found in the title record file are set up in catalog for-

TABLE OF FILING FIELDS

Ontario New Universities Library Project

\begin{tabular}{|c|c|c|c|c|c|c|c|c|c|}
\hline \multirow{3}{*}{ TrTLE RECORD } & \multicolumn{8}{|c|}{ Maximum Number of Characters in Each Filing Field } & \multirow{3}{*}{ Total } \\
\hline & \multirow[b]{2}{*}{$\begin{array}{l}\text { Entry } \\
\text { Type } \\
\text { Field }\end{array}$} & \multirow[b]{2}{*}{$\begin{array}{c}\text { Added } \\
\text { Entry } \\
\text { Field }\end{array}$} & \multirow[b]{2}{*}{$\begin{array}{l}\text { Subj. } \\
\text { Entry } \\
\text { Field }\end{array}$} & \multirow[b]{2}{*}{$\begin{array}{l}\text { Author } \\
\text { Entry } \\
\text { Field }\end{array}$} & \multirow{2}{*}{$\begin{array}{l}\text { Title } \\
\text { Main } \\
\text { Entry } \\
\text { Field }\end{array}$} & \multicolumn{2}{|c|}{ Title Field } & \multirow[b]{2}{*}{$\begin{array}{l}\text { Date of } \\
\text { Public } \\
\text { Field }\end{array}$} & \\
\hline & & & & & & $\begin{array}{c}\text { Convent. } \\
\text { Title }\end{array}$ & $\underset{\text { Title }}{\text { Actual }}$ & & \\
\hline Author Main Entry & 1 & $\ldots$. & $\ldots$ & 39 & $\ldots$ & 7 & 10 & 3 & 60 \\
\hline Title Main Entry & 1 & $\ldots$ & $\ldots$ & $\ldots$ & 56 & $\ldots$ & $\ldots$ & 3 & 60 \\
\hline Added Entry . & 1 & 39 & $\ldots$ & 10 & $\cdots \cdots$ & 7 & $\ldots$ & 3 & 60 \\
\hline Subject Entry . & $\ldots$ & $\ldots$. & 40 & 15 & $\ldots$ & 5 & $\ldots$ & $\ldots$ & 60 \\
\hline
\end{tabular}

Note that these fields are the maximum allotted. An actually shorter statement in any of these fields will transfer the balance to the following field, so that a total of sixty characters can be selected from the specified eight filing subfields in order to determine the filing arrangement. 


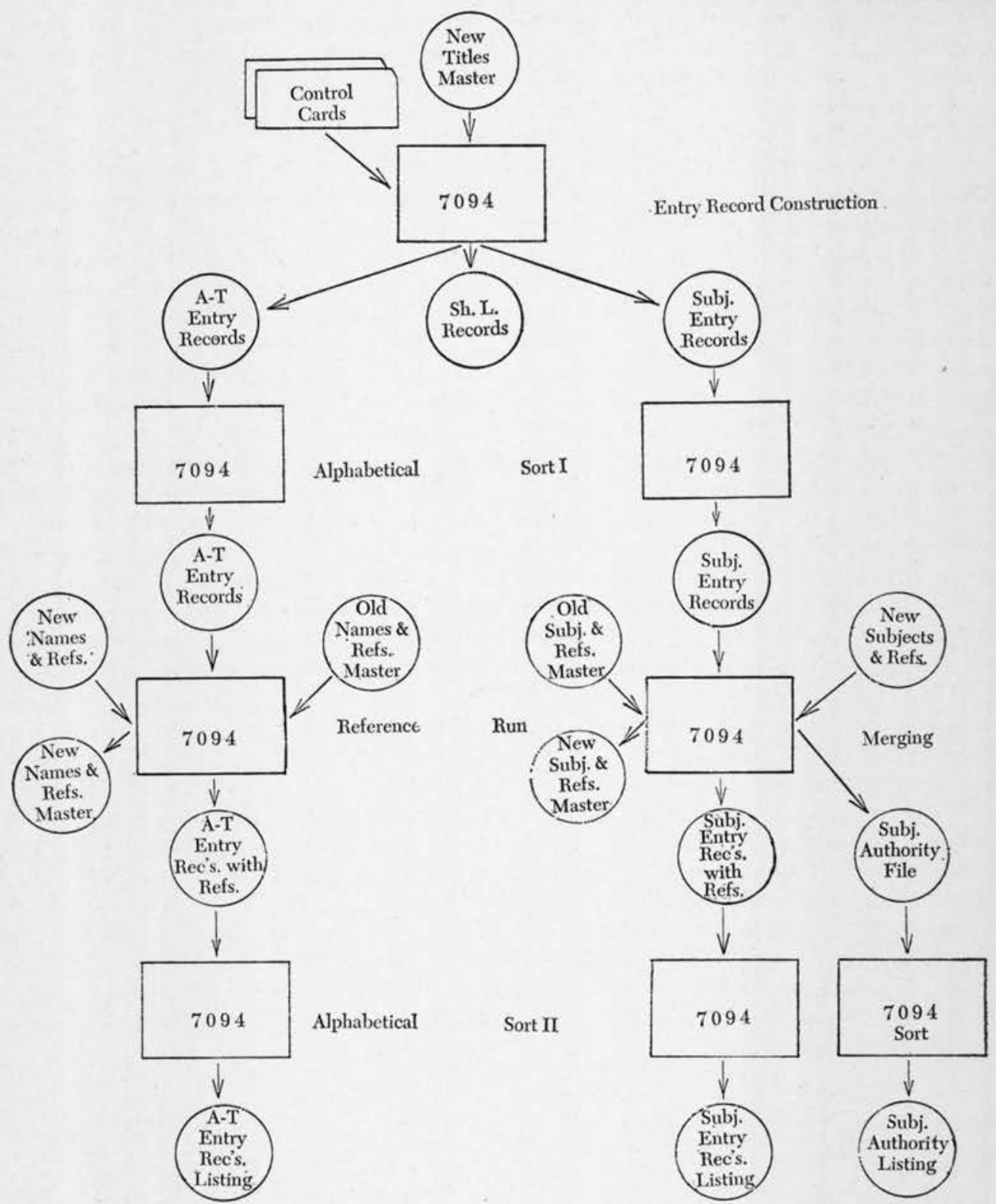

Fig. 5-Processing Chart-Trtle Record and Subject Record

mat and added to the title record file (Fig. 5). Re-sorting of this file is necessary in order to place all references in their proper alphabetical positions.

Subject entry record processing is performed in the same manner as processing of the author-title entry records. In addition an authority list of legitimate sub- ject terms with references to these terms is constructed for the convenience of the processing staff.

The last stage of the Cobol program for the 7094 processing cycle consists of setting up the output format according to the output type: card format for the shelflist records, and three-column page 
for the author-title catalog and the subject catalog (Fig. 6). This is done in the form of a 1401 tape output listing. This listing is performed on a 1403 model II printer equipped and programed to handle upper and lower case characters and diacritical marks. Each line containing diacritical marks must be printed twice using the space suppress feature of the printer.

The printed catalog page containing 110 lines of 132 characters each (105 net lines of 126 net characters) and measuring $14 \times 18 \%$ inches is too large for convenient use. Photographic reduction to 60 per cent of the original format gives good readability and convenient size (9 $\times 12$ inches). This format accommodates bibliographic information covering thirteen titles on one page of the authortitle catalog and seventeen titles per page in the subject catalog. This includes all required secondary approaches (sec- ondary entries, references, and scope notes). An unlimited number of copies of the catalog can be obtained by offset printing from the photographically reduced plate.

Issue of the book form catalogs follows a cumulative pattern. Monthly issues containing information added to the master record during the current month are prepared for each of the first two months of each quarter of the year. Quarterly cumulations are produced for the third and ninth month of the year, semi-annual cumulation for the first half of the year, and a total cumulation of the entire information store at the end of the year. This pattern represents the most acceptable ratio between the printing cost (i.e., cost of reprinting the information in successive cumulations) and the convenience of finding any given item by searching in the minimum number of catalog issues (Fig. 7).

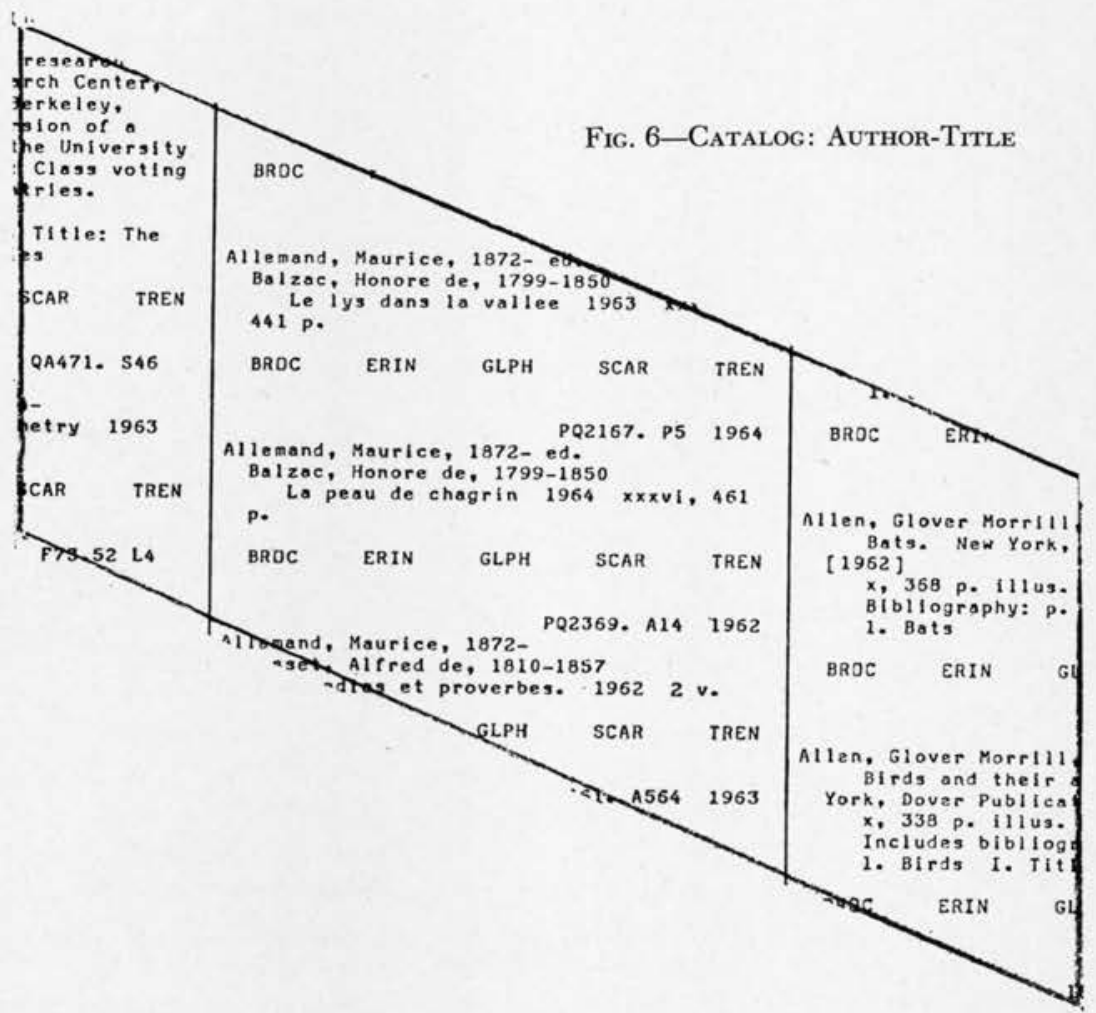




\section{Additional Bibliographic Services}

The master file of bibliographic data is capable of providing other much needed services to the library besides the production of catalogs. There are four groups of such functions which can be based on or derived from the ONULP master record of biliographic data.

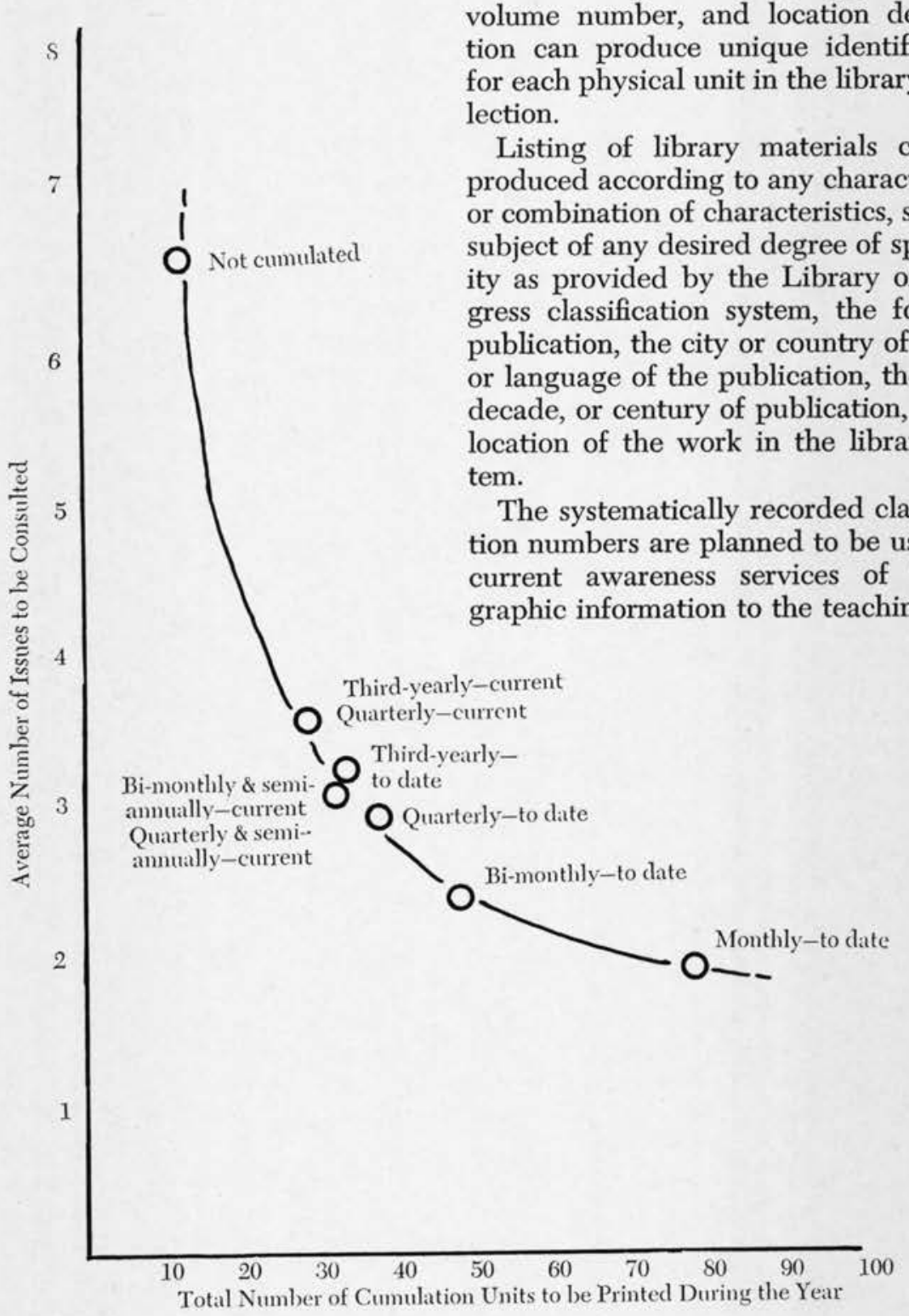

First, the master record is designed to support a number of service functions and records. The individual institutions can automatically produce book cards and other circulation records for all their materials which are recorded in the master file, since the combination of individually identified classification number, form of the publication, copy number, volume number, and location designation can produce unique identification for each physical unit in the library's colection.

Listing of library materials can be produced according to any characteristic or combination of characteristics, such as subject of any desired degree of specificity as provided by the Library of Congress classification system, the form of publication, the city or country of origin or language of the publication, the year, decade, or century of publication, or the location of the work in the library sysm.

The systematically recorded classification numbers are planned to be used for current awareness services of bibliographic information to the teaching staff

Fig. 7-Cumulation Effect and Printing Cost 


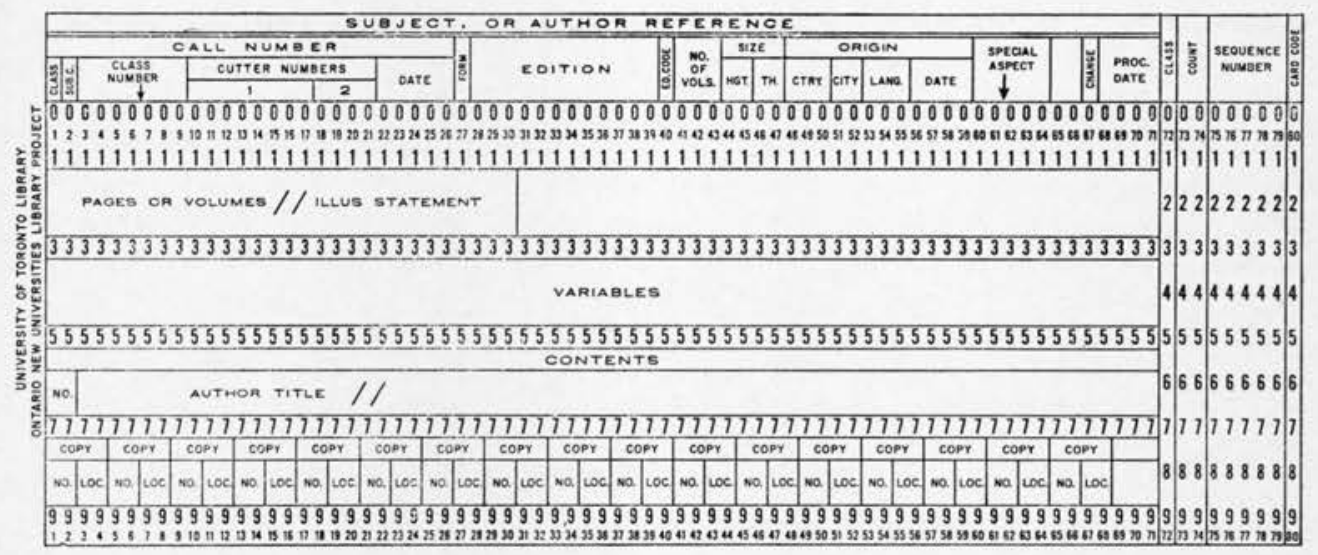

Fig. 8-Title Record CARD

of the colleges. The areas of interest (profiles) of the teaching staff would be expressed in several relatively general classification numbers. The system would compare these numbers with the specific classification numbers in the file of the recently-acquired materials selecting those items which have classification numbers equal to or more specific than those of the interest profile. The resulting lists would then be mailed periodically to the persons concerned.

The compatible data format facilitates important cooperative services. The systematic structure of bibliographic data in the master record permits flexible storage of the entire master file in a large electronic memory providing random access to this information for purposes of checking new acquisition requests against the master record, for cataloging information contained in the master record, or for receiving and transmitting bibliographic data from and to remote locations. Bibliographic reference information can be obtained from the common pool of the project. Also, information can be exchanged with other libraries using a similar compatible data format. It is expected that regional union catalog services can be based on the centralized store of bibliographic data. The master file can be compiled by centralized or cooperative efforts. The format of sys- tematically identified categories and elements of bibliographic data permit the sharing or centralizing of bibliographic processing. This cooperative effort can be further assisted by direct communication of the machine-readable bibliographic data from library to library. All these cooperative functions of automated bibliographic information control promise unlimited possibilities of application.

The third group of automated functions which are facilitated by the systematized data format of the master record is a number of analytical approaches to the bibliographical information. The detailed control of classification number values affords systematic subject approach which can respond to the entire range of specificity inherent in the Library of Congress classification system. Classification numbers are recorded in the master file oriented to a fixed location. The input form of this feature is indicated on the Hollerith card by an arrow (Fig. 8). Similarly, a system of form codes identifies every bibliographic unit (title) as monograph, serial, journal, microtext, and so on. Combined with other parameters of the data format, such as language or place of publication, this aspect lends itself to a variety of applications of analytical bibliography.

The fourth group of automated functions pertains to the control of the library 
collection. The independently functioning authority files of the master record permit complete flexibility for accommodating alternative forms of the key bibliographic elements in the master record. All variant forms are recorded in these files under the accepted standard form which alone is directly linked with the affected bibliographic data on the title record. This structure not only provides the system with an automated reference network, but it also permits compilation of various working tools in any desired format for use of the processing staff, such as lists of subject terms, or name authority lists.

For the wide range of statistical and inventory control purposes, records of required scope and format can be produced as necessary. Administrative data which derive from the format of the master record include both the information about the physical size of the library's collection and the qualitative factors connected with the growth of the collection.

An important factor in administrative decisions of every library director is the actual physical size of the collection and its integral parts. Recording of thickness of every item added to the collection is intended to facilitate calculations for such purposes. Moreover, the physical size of the collection combined with classification data can produce vital information about the distribution of shelving arrangement and capacity at any given time. Planning of library buildings and the arrangement of materials in the library can thus be based on calculations of empirical factors rather than estimates and intuition. Planned regulation of the growth of the library collection according to specific requirements can be facilitated by combining the various data elements identified in the master record. Enlightened building of research library collections which still is the weakest aspect of library administration can be made possible by periodic analysis of the collection in terms of all bibliographically qualitative aspects, such as subject matter, form of publication, periods, etc. Similarly, analyses of the use of the collection can easily be obtained and correlated with other characteristics of the collection.

\section{Conclusions and Problems}

To date the master record has been tested only for two purposes: for the production of shelflist records in card form and for the compilation of catalogs in book form. No complete evaluation of the system therefore is possible at this time. Certain general observations, however, can be made.

Throughout the design stage of the ONULP bibliographic control system it appeared that during its operation the project would not require handling of either excessively complex or large quantities of bibliographic information.

This allowed compromises to be accepted that kept the design of the system within limits of economic feasibility and immediate usefulness. No compromises were made, however, of a principal nature affecting the structure of the system. It was assumed that one of the functions of the project was to test the feasibility of such a system for potentially larger and more complex requirements which would necessitate more detailed identification of a larger number of bibliographic elements.

One of the observations which indicates a potential for important further development is the facility of the systematic structure of the bibliographic data format which is employed in the compilation of the master record to accommodate communication of bibliographic information. Such communication in digital data form may be carried out through the intermediary of punched cards, magnetic tape, teletype, or telephone network for the purposes of distribution of catalog information and for reference access to centralized stores of bibliographic information. 
This potential brings out the importance and need for a generally acceptable compatible data format for bibliographic information so that not only a generally agreed minimum of appropriately identified bibliographic data would be recorded and thus could be retrieved by any participant of a coordinated system, but also so that standardized encoding structure could make these data readily acceptable for a variety of uses by the recipient.

The data format developed for the ONULP master record has purposely maintained a maximum possible similarity in form with customary forms of bibliographic data in order to accommodate as much as possible formerly existing work patterns. The operation of the input system for the past year bears out this expectation. Only a minimum of adjustment in customary work procedures was required; the change from the customary card layout to the ONULP data sheet (Fig. 1) did not require more than a few days. The same applies to the format of the printed catalog in which the close correspondence between the customary forms and those adopted for the ONULP catalog format greatly facilitates the transition from a manual to an automated mode of operation.

The catalog compilation system includes a number of experimental features which eventually should help to evolve better methods for several difficult aspects of bibliographic data processing. The programed editing of bibliographic data which abbreviates all secondary entry records in the catalog appears to indicate the feasibility of automated editing processes as a means of adjusting bibliographic data received from an extraneous source to fit a local data file which has certain characteristics peculiar to the individual library.

The completely automated formation of all entry records for the catalogs has demonstrated the value of the unit concept in bibliographic data re-formatting. Formats of various required bibliograph- ic data have been obtained from one basic input format, the structure of which is oriented towards flexibility rather than towards preselected bibliographic requirements.

The display of the various entry records appears to indicate that in book form catalogs the customary distinction between "main" and "secondary" entries becomes less important. The structure of the master record and the ONULP catalog compilation system have taken over the control of relationships between the various approaches to the bibliographic unit (title). The catalog itself is freed of this control task. The reader consulting the catalog is primarly concerned with finding the names related to a bibliographic item, and he is usually little interested in the relative specific weight of these names connected with the item. It seems possible that the book form catalog may bring relief to the problem of "choice of entry" in particular for publications in which several persons or corporate entities, according to the present entry rules, aspire to the status of "main" entry resulting in a highly perplexing confusion.

The ONULP bibliographic control system is also designed to produce author analytical entry records for the items listed in the contents of any bibliographic unit whenever the requirement for analytical entry records is specified. For this application the facility of data processing methods is expected to provide a much needed service in an area of work which is very cumbersome and time consuming when performed by manual methods.

The printed output of the catalog compilation system is expressed in the form of one type font which contains upper case and lower case alphabetical characters, numerical characters, and the following special characters required for adequate display of bibliographic information: period, comma, colon, semicolon, question mark, apostrophe, round brackets, square brackets, diagonal slash, 
underscore, plus sign, hyphen, dollar sign, percentage, asterisk, number sign, equal sign, musical flat sign, calligraphic letter "l", quotes, ampersand, and all diacritical marks required for the Roman alphabets of all major languages. The printing of ONULP catalogs is done on an IBM 1403 model II printer for which a special print chain with the enumerated characters was developed jointly with the Florida Atlantic University library and the Yale University medical school library.

The resulting graphical display of bibliographic information leaves many things to be desired. The major non-Roman alphabets, several type fonts and sizes, and a sharper letter outline are requirements which cannot be readily met by the impact printing technique. Electromagnetically-optical methods appear to be holding promise for a widened scope and enhanced appearance and clarity of the automatically produced catalog.

Some of our existing bibliographic methods and philosophies restrict the ONULP master record and the catalog compilation system to a limited degree of specificity and exactitude of the bibliographic data which can be usefully processed and communicated. This limitation is not insignificant for approach through name entry; it is, however, severely restrictive for systematic subject approach. The design and the initial operation of the ONULP system have shown that subject headings by virtue of their structure do not lend themselves to systematic organization of concepts and their terms which are used to describe the contents of bibliographic units. Presently the only practically available method for securing a somewhat systematic subject approach to large library collections of general subject scope is through classification. This method, however, does not permit more systematic subject matter organization than our classification schemes.
It is therefore clearly indicated that the most pressing long range requirement for adequate control of bibliographic information is research into systems of entry or an equivalent to it, and in particular into systems of organization of concepts and their terminology.

Other restrictions of the ONULP system are purposely imposed and can be eliminated if desired. The present system is programed to handle only information about book materials; minor adjustments can provide for other forms, such as micro-materials or audio materials. More considerable expansion of the system is required in order to adapt it for handling large and specialized research collections: as indicated earlier, the identification of a number of categories and elements of bibliographic information has to be carried further than provided in the present data format of the ONULP system.

The ONULP bibliographic data control system has demonstrated the feasibility of the application of electronic data processing techniques to bibliographic control. Even if information retrieval, meaning mechanized access to factual information, is not yet feasible, mechanized access to macro-units of information-bibliographic control-is well within the range of immediate practical application. The ONULP system has indicated that many benefits can be derived from such an application, but it has also pointed out that serious and concentrated effort has to be directed toward research into the philosophical and theoretical bases of bibliography even more than technological aspects and techniques. Before further transition from the printed page technology to magneticallystored information technology expressed in detailed micro-units of information can take place, the basic structure and behavior of information generation and transformation have to be established for the application to macro-units of information. 